\title{
Poly(vinylimidazole-co-butyl acrylate) membranes for CO2 separation
}

Song, Ting; Deng, Jing; Deng, Liyuan; Bai, Lu; Zhang, Xiangping; Zhang, Suojiang; Szabo, Peter; Daugaard, Anders E.

\section{Published in:}

Polymer

Link to article, DOI:

10.1016/j.polymer.2018.11.058

Publication date:

2019

Document Version

Peer reviewed version

Link back to DTU Orbit

Citation (APA):

Song, T., Deng, J., Deng, L., Bai, L., Zhang, X., Zhang, S., Szabo, P., \& Daugaard, A. E. (2019).

Poly (vinylimidazole-co-butyl acrylate) membranes for $\mathrm{CO}_{2}$ separation. Polymer, 160, 223-230.

https://doi.org/10.1016/j.polymer.2018.11.058

\section{General rights}

Copyright and moral rights for the publications made accessible in the public portal are retained by the authors and/or other copyright owners and it is a condition of accessing publications that users recognise and abide by the legal requirements associated with these rights.

- Users may download and print one copy of any publication from the public portal for the purpose of private study or research.

- You may not further distribute the material or use it for any profit-making activity or commercial gain

- You may freely distribute the URL identifying the publication in the public portal 


\section{Accepted Manuscript}

Poly(vinylimidazole-co-butyl acrylate) membranes for $\mathrm{CO}_{2}$ separation

Ting Song, Jing Deng, Liyuan Deng, Lu Bai, Xiangping Zhang, Suojiang Zhang, Peter Szabo, Anders E. Daugaard

\section{in \\ polymer}

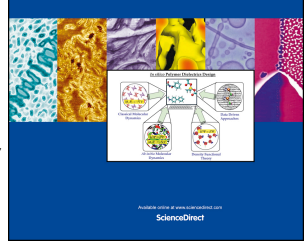

PII:

$$
\text { S0032-3861(18)31095-4 }
$$

DOI: $\quad$ https://doi.org/10.1016/j.polymer.2018.11.058

Reference: JPOL 21081

To appear in: Polymer

Received Date: 4 October 2018

Revised Date: 22 November 2018

Accepted Date: 26 November 2018

Please cite this article as: Song T, Deng J, Deng L, Bai L, Zhang X, Zhang S, Szabo P, Daugaard AE, Poly(vinylimidazole-co-butyl acrylate) membranes for $\mathrm{CO}_{2}$ separation, Polymer (2018), doi: https:// doi.org/10.1016/j.polymer.2018.11.058.

This is a PDF file of an unedited manuscript that has been accepted for publication. As a service to our customers we are providing this early version of the manuscript. The manuscript will undergo copyediting, typesetting, and review of the resulting proof before it is published in its final form. Please note that during the production process errors may be discovered which could affect the content, and all legal disclaimers that apply to the journal pertain. 


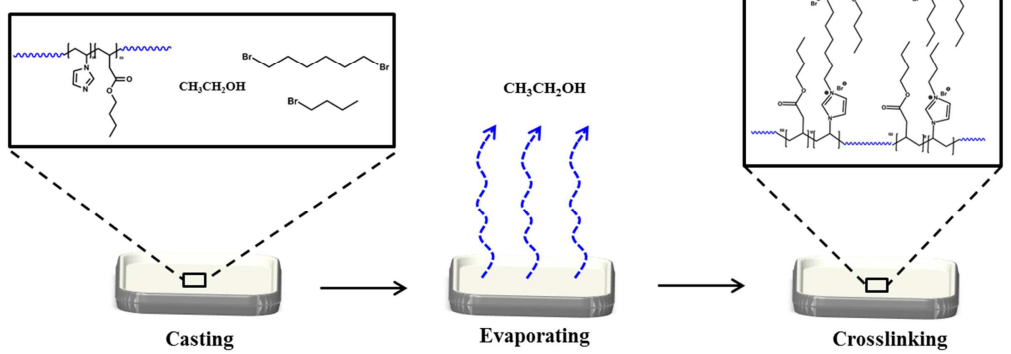




\section{Poly(vinylimidazole-co-butyl acrylate) membranes for $\mathrm{CO}_{2}$ separation}

2 Ting Song ${ }^{\mathrm{a}, \mathrm{b}}$, Jing Deng ${ }^{\mathrm{c}}$, Liyuan Deng ${ }^{\mathrm{c}}$, Lu Bai ${ }^{\mathrm{b}}$, Xiangping Zhang ${ }^{\mathrm{b}}$, Suojiang Zhang ${ }^{\mathrm{b}^{*}}$, Peter Szabo ${ }^{\mathrm{a}}$ and Anders

$3 \quad$ E. Daugaard ${ }^{\mathrm{a}^{*}}$

$4 \quad{ }^{a}$ Danish Polymer Center, Department of Chemical and Biochemical Engineering, Technical University of Denmark,

5 Building 229, 2800 Kgs. Lyngby, Denmark

$6 \quad{ }^{b}$ Beijing Key Laboratory of Ionic Liquids Clean Process, Institute of Process Engineering, Chinese Academy of Sciences,

7 Beijing, 100190, China

$8{ }^{c}$ Department of Chemical Engineering, Norwegian University of Science and Technology, 7491, Trondheim, Norway

9 Correspondence: sizhang@ipe.ac.cn or adt@kt.dtu.dk, Tel.: +45-4525-6815.

10

11

12

13

14

\section{Abstract}

Room temperature ionic liquids (RTILs) are known to exhibit high $\mathrm{CO}_{2}$ solubility, which makes them interesting candidates for separation and purification of mixed gas streams. Particularly, RTILs based on imidazoles have shown very promising results. However, membranes of the corresponding poly(RT-IL)s are inherently brittle, which makes them too fragile for use in freestanding membranes. Therefore, copolymers of $\mathrm{N}$ vinylimidazole $(\mathrm{VIm})$ and butyl acrylate $(\mathrm{BuA})$ were prepared, showing reactivity ratios of $\mathrm{r}_{\mathrm{BuA}}=1.91-2.02$ and $\mathrm{r}_{\mathrm{VIm}}=0.094-0.10$. The prepared copolymers of poly(VIm-co-BuA) with a copolymer composition of 24:76 had sufficiently low $\mathrm{T}_{\mathrm{g}}\left(-6.6^{\circ} \mathrm{C}\right)$ and were flexible enough to be used for membrane preparation. The copolymer was quarternized and crosslinked in a one-pot reaction into thin film membranes employing a mixture of mono and difunctional alkyl halides. Membranes were prepared using a mixture of 1:8, 1:2 and 1:0 of 1,6-dibromohexane and 1-bromobutane, resulting in different degrees of crosslinking. The one-pot process additionally allows incorporation of up to $16 \mathrm{wt} \%$ free RTIL $\left(\mathrm{BMIM} \mathrm{Tf}_{2} \mathrm{~N}\right)$ in the 1:0 ratio membranes. All membranes were tested for $\mathrm{CO}_{2}$ permeability (33.7-54.38 barrer), and for selectivity towards $\mathrm{N}_{2}$ and $\mathrm{CH}_{4}$. By varying the crosslinking degree, it was observed that $\mathrm{CO}_{2}$ permeability increased with decreasing the degree of crosslinking. Finally, 
24 films prepared with free RTIL led to an improvement of the gas separation performance, with $\mathrm{CO}_{2}$ permeability

25 increased from 33.71 to 38.77 barrer and $\mathrm{CO}_{2} / \mathrm{N}_{2}$ permselectivity increased from 20.81 to 27.82 .

26 Keywords: N-vinylimidazole; poly(ionic liquid); crosslinking free-standing membrane; gas separation.

\section{Introduction}

Room temperature ionic liquids (RTILs), which contain large and unsymmetrical organic cations and organic or inorganic anions, are molten salts at temperatures below $100{ }^{\circ} \mathrm{C} .[1][2]$ RTILs are popular in many fields, such as for batteries, in extractions, for dispersion, as catalyst and for separation due to their excellent chemical, thermal, and electrochemical stability, nonflammability and negligible volatility.[3-6] Additionally, the high selection of possible counter ions, being cationic or anionic as well as hydrophilic/hydrophobic, endow RTILs tunable properties to match different applications. However, industrial application of RTILs has been limited due to their high viscosity, price and liquid morphology.[7] Therefore, it is attractive to combine RTILs with membrane technology, which presents advantages of lower energy costs, reduced volatility and easy reuse, to overcome the disadvantages of RTILs.[8][9] RTILs, especially imidazole based RTILs, possess better solubility to $\mathrm{CO}_{2}$ than other light gases, such as $\mathrm{N}_{2}$ and $\mathrm{CH}_{4}$.[10] Therefore, RTILs have been widely exploited to separate $\mathrm{CO}_{2}$ from natural gas and flue gas over the past two decades. Initially, RTILs were used in supported ionic liquid membrane (SILM), where commercially available membranes have been filled with a range of RTILs, showing $\mathrm{CO}_{2}$ separation performance with ideal $\mathrm{CO}_{2}$ permeabilities of more than 1000 Barrers and $\mathrm{CO}_{2} / \mathrm{N}_{2}$ permselectivity of more than 20.[11] RTILs were immobilized in porous membranes with weak capillary forces, where loss of RTILs through leakage from the membrane support is significant.[12] This instability of SILMs under high pressure has limited their industrial application, even though SILMs have shown promising $\mathrm{CO}_{2}$ separation performance.[13] In order to overcome the shortcomings of SILMs, Noble and Gin et al. [13][14] polymerized RTILs monomers with acrylic, styrenic or vinyl imidazole on porous support membranes to form stable poly(RTIL) membranes for gas separation. Poly(RTIL) membranes possess mechanical stability and efficiently immobilize the RTILs in contrast to SILM, but exhibit much lower gas 
48 permeability and diffusivity. That is attributed to a lower fractional free volume of the dense poly(RTIL) compared to that of free RTILs.[7] According to previous investigations, combinations of poly(RTIL) and RTILs in composite membranes improved $\mathrm{CO}_{2}$ permeability by $400 \%$ relative to neat poly(RTIL) membrane due to the introduction of free RTILs.[15] However, imidazole-based poly(RTIL) are too brittle to form free-standing membranes and therefore have to be incorporated into porous polymer membranes as support or added into composites together with e.g. nanocellulose[16] or carbon nanotubes[17][18], which provides the necessary flexibility and mechanical stability to the systems. Alternatively, RTILs can also be grafted onto polymers, which possess excellent mechanical properties, such as polyimides,[19][20] polybenzimidazoles,[21][22] polyesters,[23] polyethersulfones,[24][25] polyurethane[26] to form novel and mechanically stable poly(ILs) membrane through condensation polymerization or by polymer modification.[27] In this study, we investigated the copolymerization of $\mathrm{N}$-vinylimidazole (VIm) and butyl acrylate, to facilitate preparation of soft copolymers that could act as precursors for poly(RTIL) membranes. By use of a simple one-pot quarternization and crosslinking reaction, these copolymers are used for preparation of soft, flexible, free-standing membranes, which were investigated for gas separation properties.

\section{Experimental}

\subsection{Chemicals}

Butyl acrylate, N-vinylimidazole, 2,2'-azobis(2-methylpropionitrile) (AIBN), dimethylformamide (DMF), 1, 6-dibromohexane and 1-bromobutane were purchased from Sigma-Aldrich. Ethanol was from VWR. The ionic liquid 1-butyl-3-methylimidazolium bis(trifluoromethylsulfonyl)imide ([BMIM] $\left[\mathrm{Tf}_{2} \mathrm{~N}\right]$ ) was purchased from Iolitec Ionic Liquids Technologies company. Inhibitors were removed from the monomers by passing them through neutral alumina prior to use. All other chemicals were used as received.

$$
\mathrm{CO}_{2}, \mathrm{~N}_{2} \text {, and } \mathrm{CH}_{4} \text { gases were purchased from AGA Co. Ltd with a purity grade of } 99.999 \% \text {. }
$$

2.2 General synthesis of polymers, exemplified by poly(vinylimidazole-co-butyl acrylate) (exemplified with poly(VIm-co-BuA) 48:52) 
AIBN (0.087 g, $0.53 \mathrm{mmol})$ was dissolved in DMF (10 mL) and monomers, N-vinylimidazole $(1.9 \mathrm{~g}, 20.2$ mmol) and butyl acrylate $(2.6 \mathrm{~g}, 20.3 \mathrm{mmol})$, were added into the flask. The reaction mixture was bubbled with nitrogen for $20 \mathrm{~min}$ to remove all traces of oxygen. The polymerization mixture stirred under nitrogen using a magnetic stirrer for $10 \mathrm{~h}$ at $70{ }^{\circ} \mathrm{C}$. During the polymerization the viscosity of the mixture gradually increased due to the conversion of monomer. The crude product was purified by precipitation into ether, it was redissolved in EtOH and precipitated into ether again. The product copolymer was then dried in vacuo until constant mass. Poly(vinylimidazole) (poly(VIm)) and poly(butyl acrylate) (poly(BuA)) and other copolymers were also synthesized using the general method (see supporting information for experimental and analytical data shown in supporting information SI-Fig 1-9, 12-16).

IR $\left(\mathrm{cm}^{-1}\right): 3111 \mathrm{~cm}^{-1}(\mathrm{C}=\mathrm{C}-\mathrm{H}), 3012-2844 \mathrm{~cm}^{-1}, 1451 \mathrm{~cm}^{-1}\left(-\mathrm{CH}_{2}-\right), 1727 \mathrm{~cm}^{-1}$ and $1160 \mathrm{~cm}^{-1}(\mathrm{C}=\mathrm{O}$ and $\mathrm{C}-\mathrm{O}-\mathrm{C}$ in acrylate group), $1660 \mathrm{~cm}^{-1}, 1494 \mathrm{~cm}^{-1}, 1223 \mathrm{~cm}^{-1}, 1267 \mathrm{~cm}^{-1}(\mathrm{~N}=\mathrm{C}$ and $\mathrm{C}=\mathrm{C}), 914 \mathrm{~cm}^{-1}, 664 \mathrm{~cm}^{-1}, 632 \mathrm{~cm}^{-1}$ $(\mathrm{C}=\mathrm{C}-\mathrm{H}$ and $\mathrm{N}=\mathrm{C}-\mathrm{H})$;

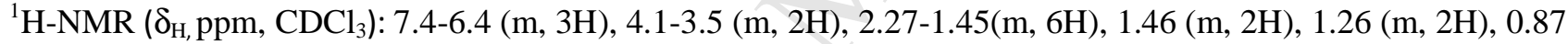
$(\mathrm{m}, 3 \mathrm{H})$.

\subsection{General procedure for preparation of crosslinked poly(VIm-co-BuA) membranes (exemplified with} the $20 \%$ crosslinked membrane).

Poly(VIm-co-BuA) (24:76, $1.5 \mathrm{~g}, 3.0 \mathrm{mmol}$ functional group) was dissolved in ethanol (12 $\mathrm{mL})$ by stirring overnight. Then 1,6-dibromohexane $(0.09 \mathrm{~g}, 0.37 \mathrm{mmol})$ and 1-bromobutane $(0.42 \mathrm{~g}, 3.01 \mathrm{mmol})$ (The details for the other compositions are showed in the supporting information) were introduced into the copolymer solution to prepare membranes with different crosslinking degree, and the mixture was stirred for additionally 1 h. The solution was degassed by ultrasonication for $10 \mathrm{~min}$ and solvent casted in a Teflon petri dish. The casting solution was allowed to evaporate at ambient conditions in a fume hood. To remove entrapped residues of solvent, the casted membrane was dried in vacuo at $65^{\circ} \mathrm{C}$ for $6 \mathrm{~h}$. Procedures for all membranes can be seen in the supporting information. 


\subsection{Preparation of $100 \%$ cross linked poly(Vim-co-BuA) membrane with 16 wt\% IL}

The membrane was prepared in accordance with the general procedure using poly(VIm-co-BuA) (24:76, 1.5 $\mathrm{g}, 3 \mathrm{mmol}$ functional group) was dissolved in ethanol $(12 \mathrm{~mL})$ by stirring overnight. Then, 1,6-dibromohexane $(0.47 \mathrm{~g}, 1.92 \mathrm{mmol})$ and $\left.[\mathrm{BMIM}]\left[\mathrm{Tf}_{2} \mathrm{~N}\right](0.38 \mathrm{~g}, 0.91 \mathrm{mmol})\right)$ were introduced in and stirred for extra $1 \mathrm{~h}$. The solution was degassed by ultrasonication for $10 \mathrm{~min}$ and casted in a Teflon petri dish after. The casting solution was allowed to evaporation at ambient conditions in a fume hood. To remove entrapped residues of solvent, the casted membrane was dried in vacuo at $65{ }^{\circ} \mathrm{C}$ for $6 \mathrm{~h}$. Membrane thickness is $122.4 \mu \mathrm{m}$.

\subsection{Characterization methods}

${ }^{1} \mathrm{H}$ Nuclear magnetic resonance (NMR) spectra of the as prepared poly(VIm-co-BuA) were carried out on a Bruker Avance $300 \mathrm{MHz}$ spectrometer using deuterated dimethylsulfoxide or chloroform as solvents. Fourier transform infrared (FT-IR) was performed with a Niclet is50 ATR spectrometer with a diamond crystal from Thermo Scientific in the range of $4000-400 \mathrm{~cm}^{-1}$. Size-exclusion chromatography (SEC) was carried out on Viscotek 200 instrument with PLgel mixed-D columns and refractive index detector. The measurement took place with THF (1 $\mathrm{ml} / \mathrm{min})$ as mobile phase at room temperature. Thermo gravimetric analysis (TGA) was performed in a nitrogen atmosphere on a Discovery TGA from TA Instruments. Differential scanning calorimetry (DSC) was performed on a Discovery DSC from TA Instruments. The thermal analyses were performed at a heating and cooling rate of $10{ }^{\circ} \mathrm{C} / \mathrm{min}$. Glass transition temperatures $\left(T_{g}\right)$ were measured at the inflection point. The mechanical properties of the membranes were tested with Electroforce (EF) 3200 series from TA instrument with displacement ratio of $2.2 \mathrm{~mm} / \mathrm{min}$. The thickness of the membranes were measured with a Digitix II thickness gauge from NSK. At least 10 points were measured for every membrane; the average value was calculated and used as the membrane thickness. The extractables from the crosslinked membranes were measured by Soxhlet extraction with ethanol for $24 \mathrm{~h}$, three times for each sample and calculated by use of eq. 1.[28] 


$$
X(\text { Soxhlet })(\%)=\text { Gel }- \text { content }=\left(\frac{M_{2}}{M_{1}}\right) \cdot 100, M_{2} \leq M_{1}
$$

\subsection{Gas permeation experiment}

The single gas permeability (P) and diffusivity coefficient (D) of all the membranes were measured using a time-lag apparatus. A detailed description of the apparatus has been published elsewhere.[29] All the gases were tested after equilibration of the membrane in vacuum for $6 \mathrm{~h}$ to remove residual gases and water in the membrane. The single gas permeation was tested in the order of $\mathrm{N}_{2}, \mathrm{CH}_{4}$ and $\mathrm{CO}_{2}$. All the measurements took place at room temperature with the upstream pressure of 2 bar and the downstream pressure of approximately 0.04 mbar. The mechanism for gas transporting through polymer membranes is known to follow a solutiondiffusion mechanism. P (Barrer=10 $10^{-10} \mathrm{~cm}^{3}(\mathrm{STP}) \mathrm{cm} \mathrm{s}^{-1} \mathrm{~cm}^{-2} \mathrm{~cm} \mathrm{Hg}^{-1}$ ) was calculated by the equation 2).

$$
P=\frac{d p}{d t} \times \frac{V}{A} \times \frac{T_{0}}{p_{0} T} \times \frac{l}{p_{1}-p_{2}}
$$

where $d p / d t\left(\mathrm{~Pa} \mathrm{~s}^{-1}\right)$ is steady state pressure increase in time $\mathrm{t}, \mathrm{V}\left(\mathrm{cm}^{3}\right)$ is downstream volume, $\mathrm{A}\left(\mathrm{cm}^{2}\right)$ represents the effective membrane area, $\mathrm{T}(\mathrm{K})$ is the temperature, $l(\mathrm{~cm})$ refers to the thickness of a membrane, $\mathrm{T}_{0}$ and $p_{0}$ is the temperature and pressure at standard conditions which is $273.15 \mathrm{~K}$ and $1.0133 \times 10^{5} \mathrm{~Pa}$, respectively.

The relationship of P, D $\left(\mathrm{cm}^{2} \mathrm{~s}^{-1}\right)$ and solubility (S) $\left(\mathrm{cm}^{3}\right.$ (STP) $\left.\mathrm{cm}^{-3} \mathrm{~cm} \mathrm{Hg}^{-1}\right)$ of the gas in the polymer membrane is described in eq. 3). [14]

$$
P=S \times D
$$




$$
D=\frac{l^{2}}{6 \theta}
$$

The ideal selectivity, $\alpha_{\mathrm{ij}}$, was calculated by the ratio of species permeability, shown as eq. 5):

$$
\alpha_{i / j}=\frac{P_{i}}{P_{j}}
$$

\section{Result and discussion}

\subsection{Synthesis of poly(VIm-co-BuA)}

Imidazoles are popular for preparation of RTILs, since these are easily converted into a range of ILs by reaction with a broad selection of alkyl halides. Correspondingly, poly(RTILs) can easily be prepared by use of Vim based RTIL monomer, which polymerizes through free radical and controlled radical conditions. Poly(VIm) is a semicrystalline polymer, which is extremely brittle, which limits its application in many fields. It is also not possible to form free standing membranes consisting solely of poly(VIm) due to this brittleness. It was recently shown that direct 3D printing of mixtures of VIm and $\mathrm{BuA}$ result in a material with a significantly reduced brittleness[30]. Since, the copolymer composition from free radical copolymerization of BuA and VIm in solution has not been investigated, the copolymer reactivity ratios were determined by preparation of a range of different copolymers from different feed compositions. The structure of the prepared polymers was confirmed with FT-IR and ${ }^{1} \mathrm{H}$ NMR. The FT-IR spectra of poly(VIm), in Fig. 1, exhibits the characteristic peaks of VIm, where the peak at $3111 \mathrm{~cm}^{-1}$ is assigned to the $\mathrm{C}-\mathrm{H}$ stretching in the imidazole ring, while the peaks at $1660 \mathrm{~cm}^{-1}$, $1494 \mathrm{~cm}^{-1}$ are assigned to $\mathrm{C}=\mathrm{N}$ and $\mathrm{C}-\mathrm{C}$ stretching in the imidazole ring as well as peaks from ring vibrations at $1282 \mathrm{~cm}^{-1}$ and $1239 \mathrm{~cm}^{-1}$. Moreover, the characteristic peaks of poly(BuA) are also shown in Fig. 1, the peaks range of $3011-2827 \mathrm{~cm}^{-1}$, at $1451 \mathrm{~cm}^{-1}$ and $1381 \mathrm{~cm}^{-1}$ represent the $\mathrm{C}-\mathrm{H}$ of methyl and methylene groups symmetric and asymmetric stretching. The peaks at $1727 \mathrm{~cm}^{-1}$ and $1154 \mathrm{~cm}^{-1}$ are related to stretching vibration of $\mathrm{C}=\mathrm{O}$ and $\mathrm{C}-\mathrm{O}-\mathrm{C}$ in acrylate group. The poly(VIm-co-BuA) FT-IR spectra shows peaks from both poly(VIm) and poly $(\mathrm{BuA})$, though the intensity of peaks originating from VIm are generally weaker than the peaks from 
155 poly(BuA). The hygroscopicity of PVIm [31] results in traces of water being observed in both poly(VIm) and 156 poly(VIm-co-BuA) IR spectra, even though the samples were dried prior to analysis.

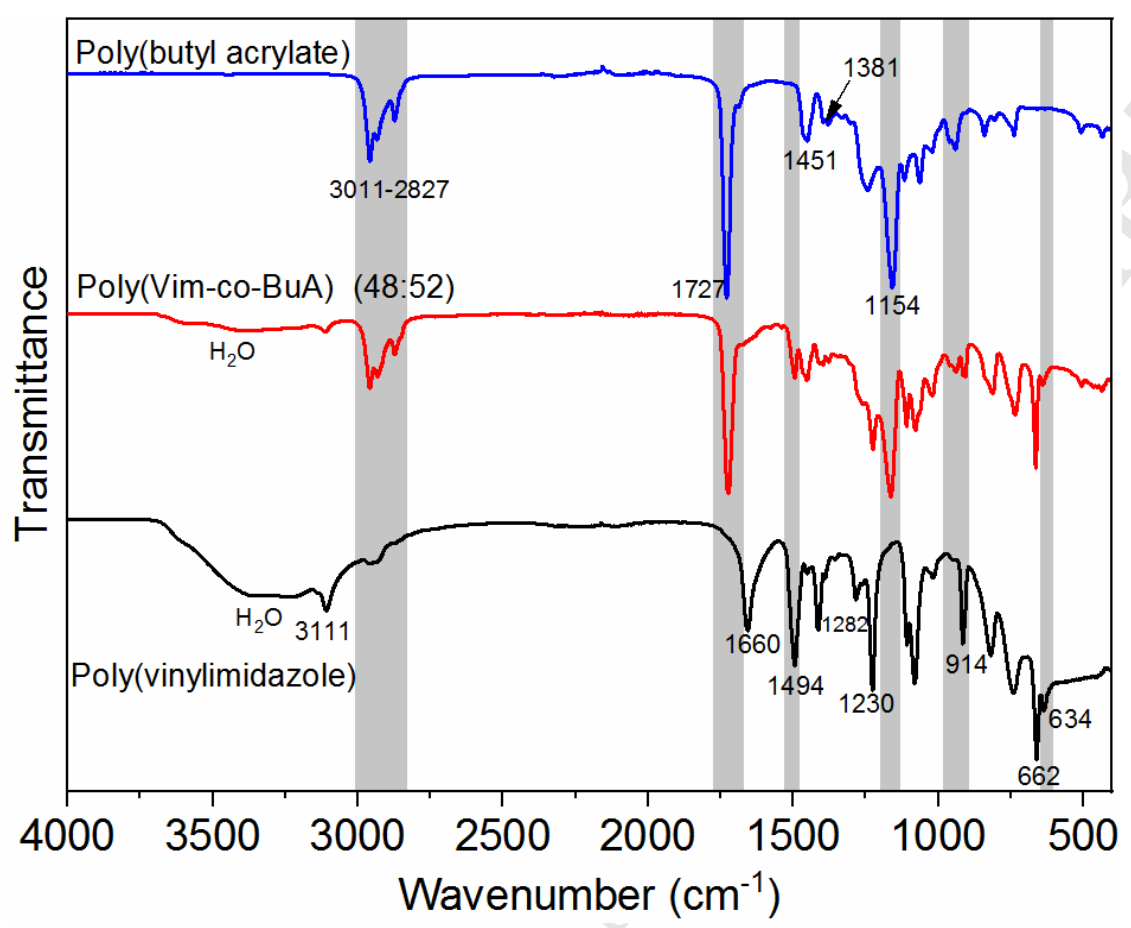

Fig. 1 The FT-IR spectra of poly(VIm), poly(VIm-co-BuA) (48:52) and poly(BuA).

The molar composition of the copolymer was calculated from ${ }^{1} \mathrm{H}$ NMR, where the molar fraction of VIm was determined from the integration of the imidazole protons at $\delta_{\mathrm{H}}$ 7.4-6.4 ppm relative to the methylene protons $161\left(\delta_{\mathrm{H}} 4.1-3.5 \mathrm{ppm}\right)$ in BuA (as shown in Fig. 2). For instance, the molar fraction of VIm in poly(VIm-co-BuA) 162 prepared from a feed composition of 50:50 VIm:BuA is $48 \mathrm{~mol} \%$. 

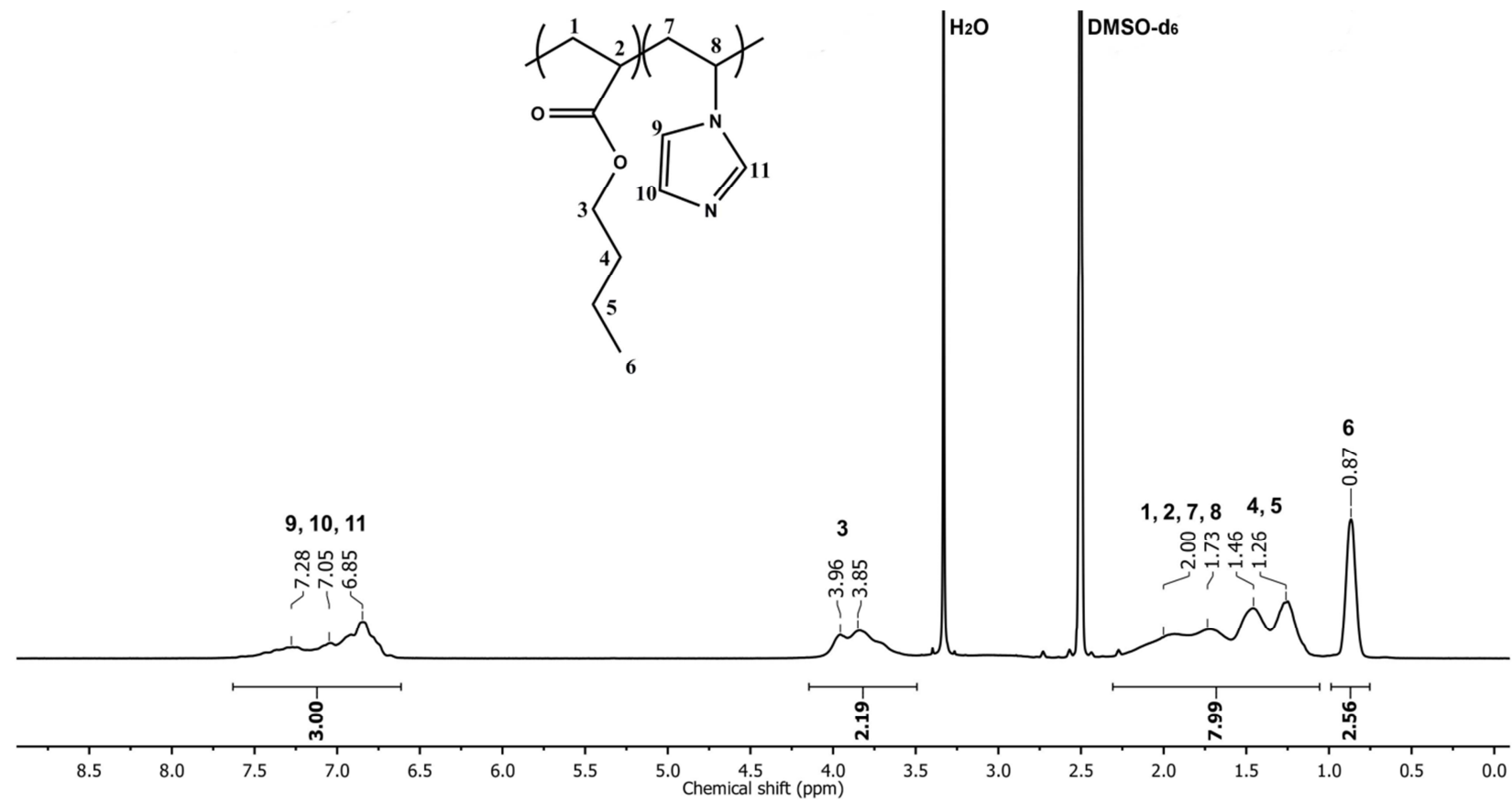

Fig. $2{ }^{1} \mathrm{H}$ NMR spectrum of poly(VIm-co-BuA) (48:52) run in DMSO- $d_{6}$.

167 on a series of copolymerizations of BuA and VIm with 10, 30, 50, 70 and $90 \mathrm{~mol} \% \mathrm{BuA}$, which were terminated 168 at low conversion to ensure constant feed composition. From ${ }^{1} \mathrm{H}$ NMR of the initially formed products of 169 poly $(\mathrm{VIm}-\mathrm{co}-\mathrm{BuA})$, the copolymer content of $\mathrm{BuA}\left(\mathrm{F}_{1}\right)$ and $\mathrm{VIm}\left(\mathrm{F}_{2}\right)$ could be determined. Based on a non170 linear least squares (NLLSQ) fit and the method of Kelen and Tüdos,[32][33] the copolymer reactivity ratios 171 were calculated as shown in Fig. 3. 

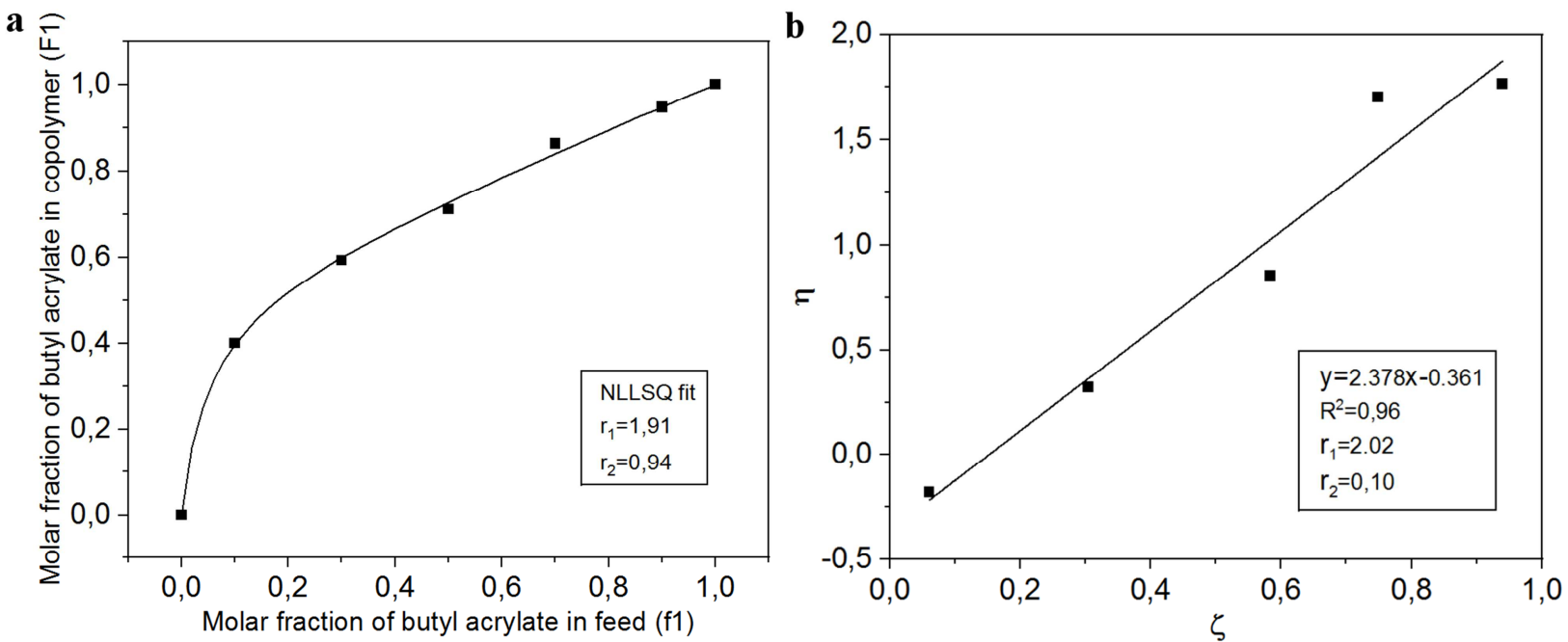

Fig. 3: a) Poly(VIm-co-BuA) composition diagram and NLLSQ fit. b) Kelen-Tüdos plot of poly(VIm-co-BuA)

The molar fraction of BuA in the feed $\left(f_{1}\right)$ versus that in the copolymer $\left(F_{1}\right)$ (shown in Fig. 3 (a)), shows a clear deviation from ideal copolymerization. The initially formed copolymer will have a higher content of BuA relative to VIm compared to the feed ratio. This is directly reflected in the reactivity ratios determined by the NLLSQ fit $\left(r_{\mathrm{BuA}}=1.91\right.$ and $\left.\mathrm{r}_{\mathrm{VIm}}=0.094\right)$ and by the method of Kelen and Tüdos $\left(\mathrm{r}_{\mathrm{BuA}}=2.02\right.$ and $\left.\mathrm{r}_{\mathrm{VIm}}=0.10\right)$ for BuA and VIm, respectively. Even though these reactivity ratios deviate from ideal copolymerization, it is possible to obtain copolymers containing both repeating units, and therefore to use them for crosslinking into membranes.

A range of different copolymers of $\mathrm{Vim}$ and $\mathrm{BuA}$ was therefore prepared to determine the optimal copolymer compositions for preparation of free standing membranes with a high VIm content and a sufficient flexibility. The physical appearance of the prepared polymers is shown in the supporting information, SI-Fig 10. The polymers have an amphiphilic nature, which unfortunately prevents SEC analysis of the compositions with more than 24 mol\% VIm in the copolymer (SEC in both THF and salted DMF has been tried). SEC of the 24 mol\% VIm copolymer displays only a single peak, corroborating that a true copolymerization took place (SI-Fig 9). Thermal characterization of the copolymers was conducted by TGA and DSC (see Figure 4). 

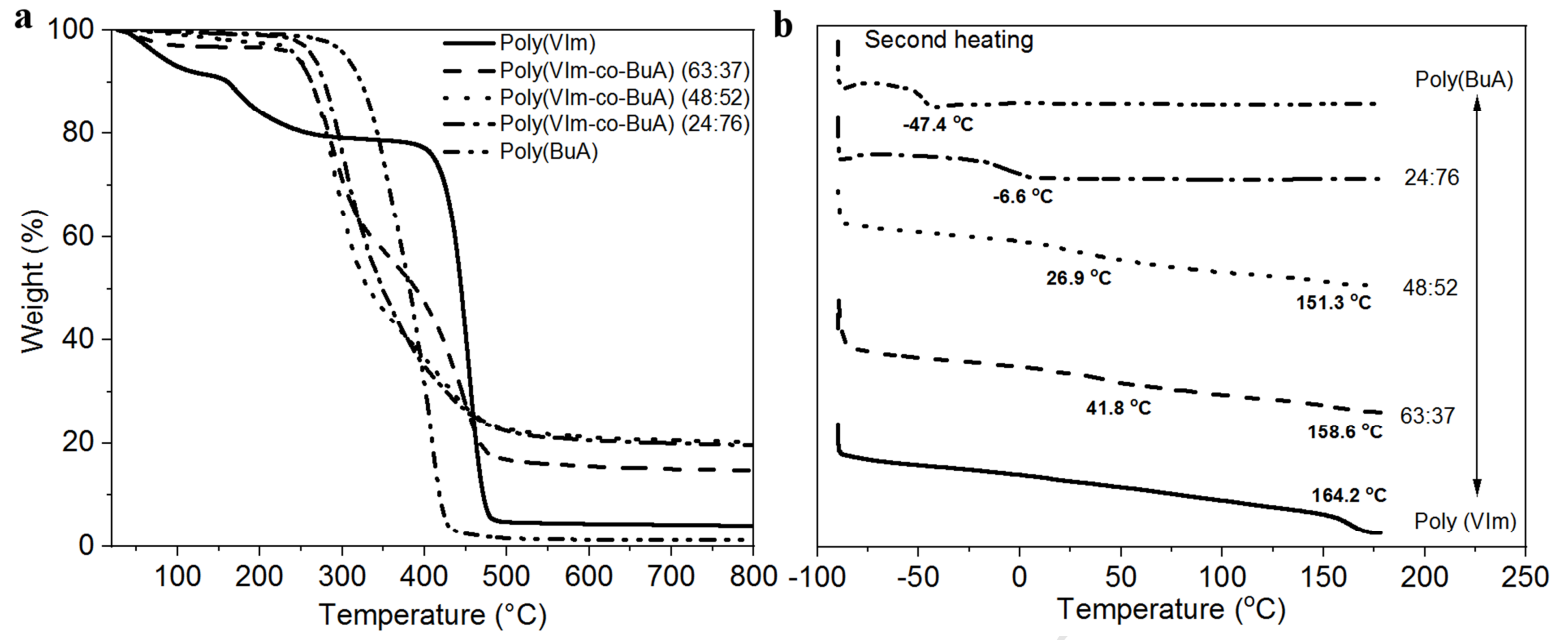

Fig. 4 Thermogravimetric analysis (a) and DSC thermograms showing second heating cycle (b) of poly(VIm), poly(BuA) and copolymers with different composition.

The TGA analysis (shown in Fig. 4(a)) illustrates the hygroscopic nature of poly(Vim), where there is a very clear weight loss of water in the initial phase of the analysis for the homopolymer of Poly(Vim). With incorporation of $\mathrm{BuA}$ in the copolymers, this is reduced, though there is a minor weight loss observed, in-line with the amount of VIm in the copolymers. The thermal degradation of all the copolymers takes place in a twostep behaviour, reflecting the content of the two monomers, and for all of the copolymers it is initiated at a lower temperature compared to the pure homopolymers $(\operatorname{Poly}(\operatorname{Vim})$ or Poly $(\mathrm{BuA}))$, though this is still sufficiently high to permit application in gas-membranes.

The introduction of BuA provided the required flexibility for the copolymers (see DSC thermograms in Figure 4(b)). An interesting detail can be seen from the first heating curve in the DSC analysis (SI-Fig 11), where the absorbed water results in an evaporation. After evaporation of the water, one glass transition $\left(\mathrm{T}_{\mathrm{g}}\right)$ is observed for the homopolymers $\left(-47.2{ }^{\circ} \mathrm{C}\right.$ for Poly(BuA) and $164{ }^{\circ} \mathrm{C}$ for Poly(VIm)), while the copolymers show intermediate glass transition temperatures. For the two systems with a high content of VIm (48 and 63 mol\%), two thermal transitions can be observed $26.9{ }^{\circ} \mathrm{C}$ and $151.3{ }^{\circ} \mathrm{C}$ as well as $41.8^{\circ} \mathrm{C}$ and $158.6{ }^{\circ} \mathrm{C}$, respectively. This could indicate formation of free Poly(Vim) or formation of a tapered copolymer (though this cannot be confirmed without SEC analysis). From all the prepared copolymers, poly(VIm-co-BuA) with ratio of 24:76 has 


\subsection{Preparation of free-standing poly(VIm-co-BuA) membranes}

Poly(RTIL) membranes were prepared from the 24:76 VIm:BuA copolymer (poly(VIm-co-BuA)) by direct

Scheme 1.

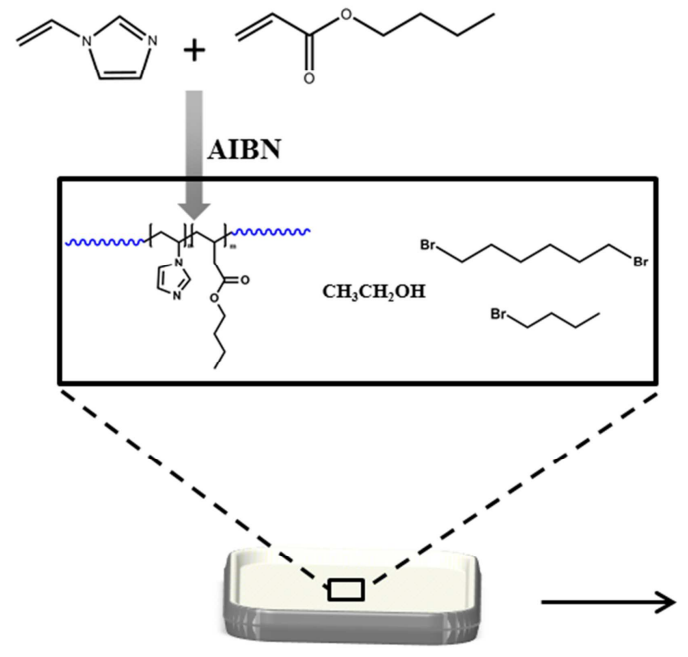

Casting

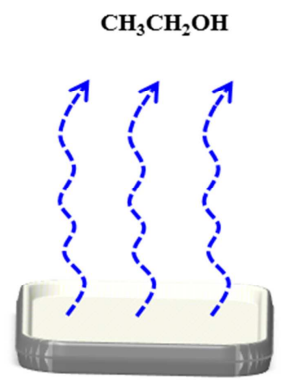

Evaporating

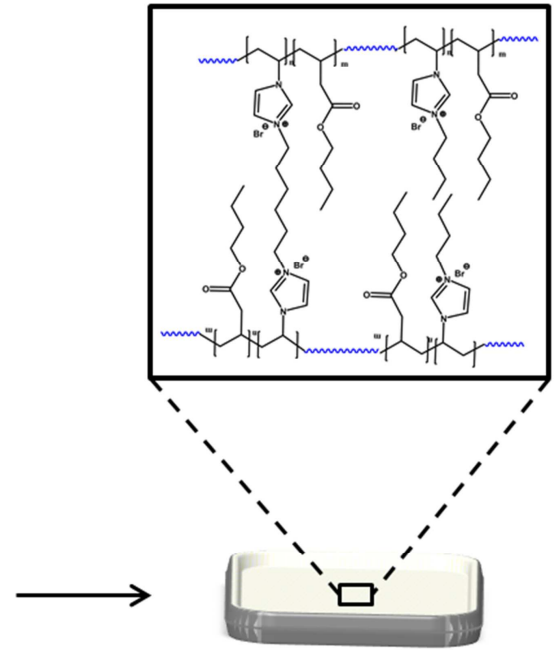

Crosslinking

Scheme 1 Copolymer preparation and one-pot casting and crosslinking of membranes.

215 kinds of crosslinked membranes were prepared in this work, the so-called $20 \%, 50 \%$ and $100 \%$ crosslinked membranes have been prepared using a 1:8, 1:2 or a 1:0 ratio of 1, 6-dibromohexane to 1-bromobutane. By

217 varying the ratio between cross-linker (1,6-bromohexane) and blocking agent (1-bromobutane), membranes with different crosslinking degree were obtained, while maintaining a similar IL character. 
Any unreacted blocking agent or cross-linker was removed in a vacuum oven after crosslinking, resulting in membranes with a low soluble fraction $(<10 \%)$ and very high gel fractions $(>90 \%)$, which was determined through Soxhlet extraction in ethanol, as shown in Table 1. Free IL in membranes is known to increase the permeability of $\mathrm{CO}_{2}$, and addition of free IL into the one-pot process was therefore also tested. BMIM $\mathrm{Tf}_{2} \mathrm{~N}$, which is one of the most commonly used and commercially available RTILs for $\mathrm{CO}_{2}$ separation,[15][34][35] was selected in this work. It was possible to add up to $16 \mathrm{wt} \%$ free $\mathrm{RTIL} B \operatorname{mim} \mathrm{Tf}_{2} \mathrm{~N}$ in the one-pot process using $100 \%$ cross linker. Free IL hindered the crosslinking reaction, and it was therefore only possible to add free IL to this membrane composition and membranes with higher free IL content could not be prepared.

There is no obvious difference observed in the FT-IR spectra of membranes with different crosslinking degree (shown in Fig. 5 (a)), since these membranes are effectively chemically equivalent. Fig. 5 (b) shows the FT-IR spectra of the $100 \%$ crosslinked membrane, $100 \%$ crosslinked membrane with free ionic liquid BMIM $\mathrm{Tf}_{2} \mathrm{~N}$ and the ionic liquid, BMIM $\mathrm{Tf}_{2} \mathrm{~N}$. It can be seen that the peaks of $100 \%$ crosslinked membrane with free

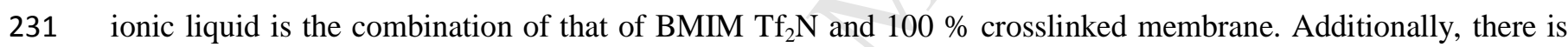
232 no shift of the peaks, indicating that there are no chemical interaction between the membrane network and the 233 ionic liquid.
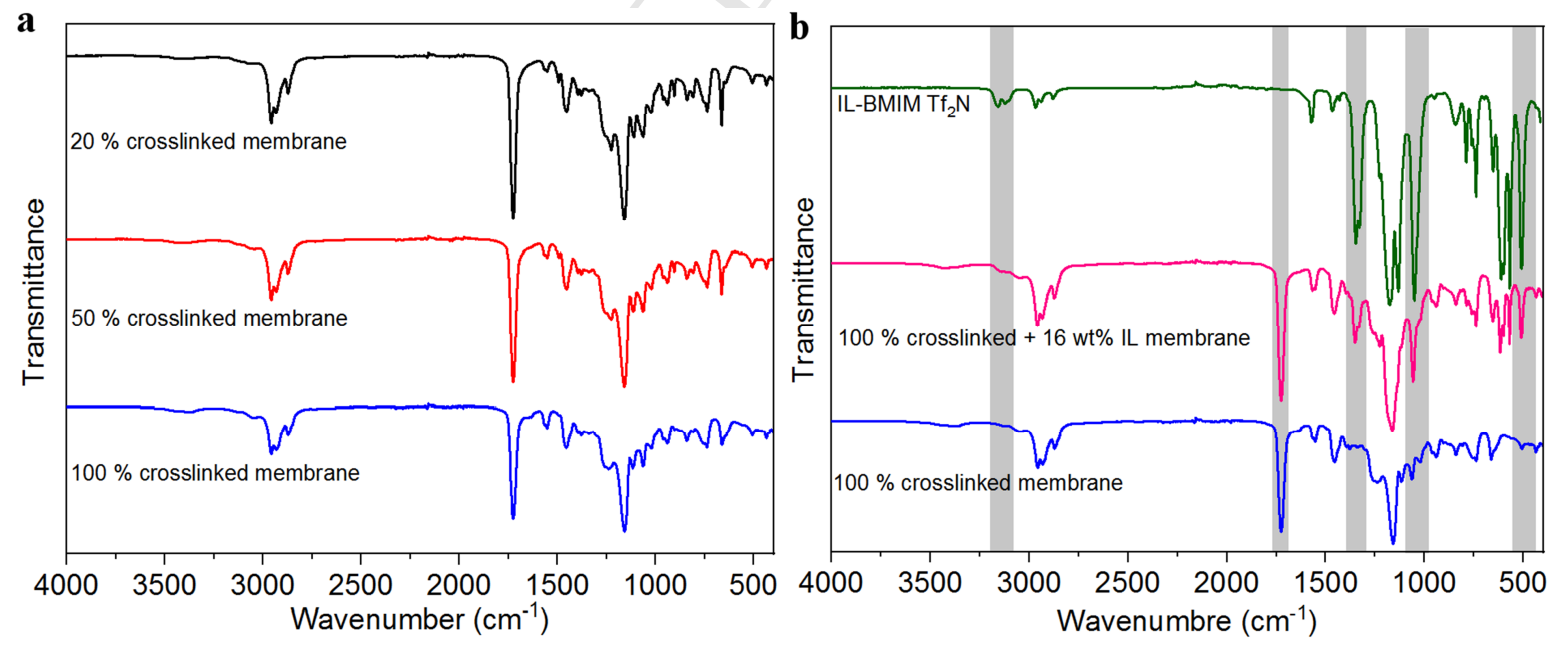
Fig. 5 FT-IR spectra of all the prepared membranes with 20, 50 and $100 \%$ cross linker (a) as well as the $100 \%$ crosslinked membrane with free ionic liquid and the ionic liquid BMIM $\mathrm{Tf}_{2} \mathrm{~N}(\mathrm{~b})$.

\section{$237 \quad 3.3$ Thermal properties}

Thermogravimetric analysis of the membranes (see Figure 6) show an even earlier onset of decomposition 240 crosslinking. This is attributed to the presence of the imidazolium salts in the polymer backbone, which is the 241 only change of the material after crosslinking. For the membranes, the first stage of weight loss is observed 242 between $220-350{ }^{\circ} \mathrm{C}$ corresponding to decomposition of the cross linker and the acrylate part of the polymer 243 backbone; while the second degradation between $350-530{ }^{\circ} \mathrm{C}$ is attributed to decomposition of the imidazole ring 244 and the polymer backbone, as has also been observed in other imidazole systems.[36] The residue after thermal 245 degradation is constant for all the membranes, indicating that this relates to the copolymer composition and not 246 the cross linker/butyl bromide ratio. In the case of additional free IL, this residue is reduced corresponding to the $24716 \mathrm{wt} \%$ of IL. The thermal stability of the all membranes is concluded to be sufficient for these materials to be 248 applicable for gas separation membranes, where temperatures between $25-75{ }^{\circ} \mathrm{C}$ of representative flue gas are 249 expected.[37] 


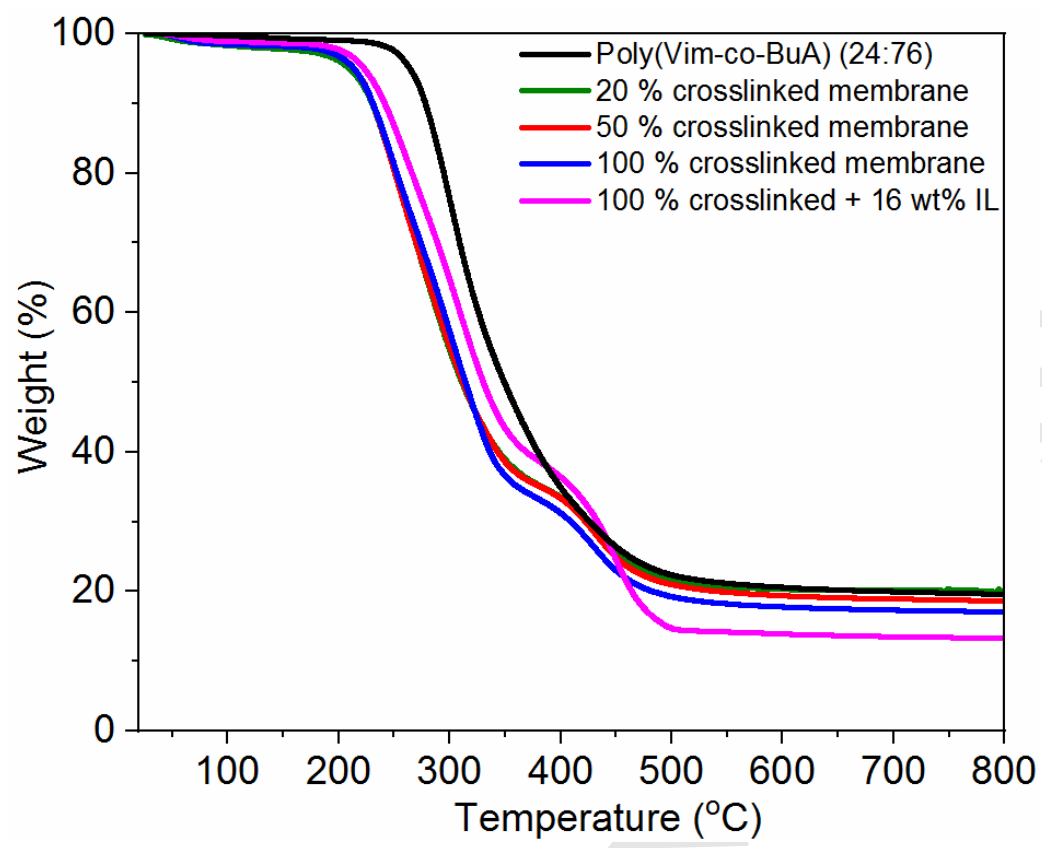

Fig. 6 TGA of poly(VIm-co-BuA) (24:76) and all the prepared membranes.

The thermal properties of the crosslinked membranes were also investigated by DSC (SI-Fig 17-20). From the first heating curve in the DSC analysis of the membranes, evaporation of water can be seen in all of the membranes, which is attributed to the hygroscopic nature of systems containing Vim and the hydrophilic property of ILs with halogen as counter ion. However, on the second heating curve, it is not possible to identify glass transition temperatures for any of the membranes. Crosslinking of the membranes was expected to result in a minor increase in glass transition temperature compared to the original copolymer, as is well known from other curing reactions.[38] All of the membranes appear soft and flexible, which indicate that the apparent glass transition temperatures is below RT (see picture of films in SI-Fig 21). This can either be a result of an actual low glass transition temperature, or a result of water plasticizing the crosslinked membranes.

\subsection{Mechanical property of crosslinked poly(VIm-co-BuA) membrane}

The mechanical properties of the membranes were evaluated by tensile testing. The stress-strain curve of the membranes is shown in supporting information SI-Fig 27. Young's modulus (MPa), Tensile strength (MPa) and elongation at break (\%) for the membranes are summarized in Table 1. 
Table 1 Gel fraction and mechanical properties of membranes.

Gel fraction $\quad$ Young's modulus $\quad$ Tensile strength $\quad$ Elongation at break

(MPa)

(MPa)

$(\%)$

\begin{tabular}{ccccc}
\hline $20 \%$ & $95.77 \pm 0.1$ & 0.0015 & 0.024 & $>53$ \\
$50 \%$ & $97.39 \pm 0.39$ & 0.0135 & 0.061 & $>53$ \\
$100 \%$ & $98.41 \pm 0.03$ & 0.0395 & 0.11 & 29.8 \\
$100 \%+16 \mathrm{wt} \% \mathrm{IL}$ & $85.35 \pm 0.18$ & 0.0034 & 0.056 & 39.2 \\
\hline
\end{tabular}

Young's modulus was determined from the slope of the stress-strain curve, and it clearly increases with increasing degree of crosslinking. In addition, Young's modulus of the membrane with IL is observed to be between that of the $20 \%$ and $50 \%$ crosslinked membranes, because of the plasticizing effect. The $100 \%$ crosslinked membrane and $100 \%$ crosslinked membrane with 16 wt $\%$ IL showed elongations at break of $29.8 \%$

271 and $39.2 \%$, respectively. However, the less crosslinked systems could not be extended to their breaking points 272 due to instrument limitations, resulting in extensions at break above 53\%. All of the membranes exhibit 273 mechanical properties that enable them to be used for gas-phase membranes.

\subsection{Gas permeation properties}

The gas separation performances of all the membranes were evaluated with a single gas apparatus. The permeability of $\mathrm{CO}_{2}, \mathrm{~N}_{2}$ and $\mathrm{CH}_{4}$ and permselectivities of $\mathrm{CO}_{2} / \mathrm{N}_{2}$ and $\mathrm{CO}_{2} / \mathrm{CH}_{4}$ are shown in Table 2, while 277 solubility and diffiusivity of $\mathrm{CO}_{2}, \mathrm{~N}_{2}$ and $\mathrm{CH}_{4}$ are shown in Table 3. In a comparable study by Gabriel Zarca et 278 al.,[39] of a supported poly[ $\left.\mathrm{C}_{4} \mathrm{vim}\right]\left[\mathrm{Tf}_{2} \mathrm{~N}\right]^{-}$membrane, they observed a $\mathrm{CO}_{2}$ permeability of 5.2 barrer with $\mathrm{CO}_{2} / \mathrm{N}_{2}$ permselectivities of 17.3 . The $\mathrm{CO}_{2}$ permeability of membranes prepared in this work ranges from 33.71 to 54.38 , which is an increase of 6.5 to 10.5 times, with $\mathrm{CO}_{2} / \mathrm{N}_{2}$ permselectivities of more than 20 , even though

281 halogen counterions are known to have significantly lower $\mathrm{CO}_{2}$-philicity than $\mathrm{Tf}_{2} \mathrm{~N}^{-}$counterions. This increased $282 \mathrm{CO}_{2}$ permeability is attributed to the introduction of $\mathrm{BuA}$, which leads to a much lower glass transition 
temperature of the membranes. At the same time, it also gave higher fractional free volume, which is known to be beneficial for gas transportation. [40][41] Additionally, the oxygen in the acrylate ester group and its ability to interact with $\mathrm{CO}_{2,[42]}$ could also be an explanation for the improvement of $\mathrm{CO}_{2}$ permeability.

Table 2 The permeability of $\mathrm{CO}_{2}, \mathrm{~N}_{2}$ and $\mathrm{CH}_{4}$ and permselectivities of $\mathrm{CO}_{2} / \mathrm{N}_{2}$ and $\mathrm{CO}_{2} / \mathrm{CH}_{4}$.

\begin{tabular}{|c|c|c|c|c|c|}
\hline \multirow[b]{2}{*}{ Membrane } & \multicolumn{3}{|c|}{ Permeability (Barrer) } & \multicolumn{2}{|c|}{ Permselectivity } \\
\hline & $\mathrm{CO}_{2}$ & $\mathrm{~N}_{2}$ & $\mathrm{CH}_{4}$ & $\alpha_{\mathrm{CO}_{2} / \mathrm{N}_{2}}$ & $\alpha_{\mathrm{CO}_{2} / \mathrm{CH}_{4}}$ \\
\hline $20 \%$ & 54.38 & 11.79 & 6.16 & 4.61 & 8.83 \\
\hline $50 \%$ & 44.35 & 2.05 & 5.16 & 21.63 & 8.59 \\
\hline $100 \%$ & 33.71 & 1.62 & 3.64 & 20.81 & 9.19 \\
\hline $100 \%+16 \mathrm{wt} \% \mathrm{IL}$ & 38.77 & 1.39 & 4.18 & 27.82 & 9.28 \\
\hline
\end{tabular}

Table 2 also shows that the gas permeability increases for membranes prepared with lower amounts of cross linker (50\% and $20 \%$ mixtures), where the permeability of $\mathrm{CO}_{2}$ increased from 33.71 to 44.35 barrer without compromising permselctivity. The increase of $\mathrm{CO}_{2}$ permeability was favored from both $\mathrm{CO}_{2}$ diffusivity and solubility (as shown in Table 3). The increase in diffusivity, is attributed to the higher fractional free volume of the less crosslinked membranes, which is consistent with results of other systems.[43] Membranes prepared with $20-50 \%$ cross linker show an increased solubility of $\mathrm{CO}_{2}$, which is surprisingly not matched for the membrane with free IL. This leads us to hypothesize that this increase must be due to a greater interaction of $\mathrm{CO}_{2}$ with the polymer bound RTIL introduced with the blocking agent. Additionally, the increase of $\mathrm{CO}_{2}$ permeability is higher than that of $\mathrm{N}_{2}$ and $\mathrm{CH}_{4}$, which illustrates that the poly(RTIL) membranes have better affinity to $\mathrm{CO}_{2}$. The observed difference in mechanical properties and lower degree of crosslinking in the membranes with $20 \%$ cross linker leads to a considerably more open structure, resulting in an increase in permeability, diffusivity and solubility of $\mathrm{N}_{2}$ and $\mathrm{CH}_{4}$ as shown in Table 2 and 3.

Table 3 The diffusivity and solubility of $\mathrm{CO}_{2}, \mathrm{~N}_{2}$ and $\mathrm{CH}_{4}$ in the crosslinked poly(VIm-co-BuA) membranes.

Membrane $\quad$ Diffusivity $\left(\times 10^{7} \mathrm{~cm}^{2} \mathrm{~s}^{-1}\right) \quad$ Solubility $\left(\mathrm{cm}^{3}(\mathrm{STP}) \mathrm{cm}^{-3} \mathrm{~atm}^{-1}\right)$




\begin{tabular}{|c|c|c|c|c|c|c|}
\hline & $\mathrm{CO}_{2}$ & $\mathrm{~N}_{2}$ & $\mathrm{CH}_{4}$ & $\mathrm{CO}_{2}$ & $\mathrm{~N}_{2}$ & $\mathrm{CH}_{4}$ \\
\hline $20 \%$ & 1.95 & 2.42 & 1.91 & 2.12 & 0.37 & 0.25 \\
\hline $50 \%$ & 1.82 & 1.90 & 2.21 & 1.85 & 0.082 & 0.18 \\
\hline $100 \%$ & 1.44 & N/A & 1.49 & 1.78 & N/A & 0.19 \\
\hline $100 \%+16 \mathrm{wt} \% \mathrm{IL}$ & 1.95 & N/A & 1.57 & 1.51 & N/A & 0.20 \\
\hline
\end{tabular}

\subsubsection{Composite membrane with free IL}

Based on previous investigations, introduction of free ionic liquid is an efficient way to improve the $\mathrm{CO}_{2}$ separation performance of poly(IL) membranes.[14][35] In this work, 16 wt $\%$ BMIM $\mathrm{Tf}_{2} \mathrm{~N}$ was added to the $100 \%$ crosslinked membrane. Table 2 and 3 show gas separation behaviors of membranes before and after the addition of free IL. The gas permeability and permselectivity of the membrane with free IL increased as expected. At the same time, the diffusivity coefficient increased from 1.44 to $1.95 \times 10^{7} \mathrm{~cm}^{2} \mathrm{~s}^{-1}$, but the solubility coefficient decreased from 1.78 to $1.51 \mathrm{~cm}^{3}$ (STP) $\mathrm{cm}^{-3} \mathrm{~atm}^{-1}$. This was an unexpected result, which illustrates that the increased permeability is a result of the added RTIL acting as a plasticizer of the poly(RTIL) membrane (diffusivity) as observed from the other systems, and apparently cannot be attributed to the high $\mathrm{CO}_{2}$ solubility of free RTIL.

\section{Conclusion}

A series of copolymers of VIm and BuA were synthesized in the work. Poly(VIm-co-BuA) (24:76) was found to be the best compromise between content of VIm and thermal properties $\left(\mathrm{T}_{\mathrm{g}}=-6.6{ }^{\circ} \mathrm{C}\right)$, and it was therefore used for preparation of free-standing poly(RTILs) membranes. Membranes were prepared by crosslinking poly(VIm-co-BuA) with a combination of 1, 6-dibromohexane (cross linker) and 1-bromobutane

317 permeability was increased from 33.7 barrer for the membrane prepared with only cross linker to 54.4 barrer for 318 the membrane prepared from a 1:4 mixture of cross linker and blocking agent. However, this more flexible membrane also showed a significantly increased permeability of $\mathrm{N}_{2}$. An optimal balance between permeability 
and selectivity was observed for the membrane prepared with 50\% cross linker, which showed both a high

321 permeability to $\mathrm{CO}_{2}$ (44.4 barrer) as well as a good permselectivity of $\mathrm{CO}_{2}$ over $\mathrm{N}_{2}$ of 21.6. An ion gel was also prepared in this work by introducing $16 \mathrm{wt} \%$ free $\mathrm{IL} \mathrm{BMIM} \mathrm{Tf}_{2} \mathrm{~N}$ in the $100 \%$ cross linker membrane, showing increased $\mathrm{CO}_{2}$ permeability from 33.71 to 38.77 barrer and increased permselectivity of $\mathrm{CO}_{2} / \mathrm{N}_{2}$ from 20.81 to 27.82.

The results showed that the prepared membranes have potential to separate $\mathrm{CO}_{2}$ from flue gas and natural gas. Compared to the analogous neat poly(RTIL) membranes, both the permeability of $\mathrm{CO}_{2}$ and the permselectivity of $\mathrm{CO}_{2} / \mathrm{N}_{2}$ were increased.

\section{Acknowledgement}

The Institute of Process Engineering in Beijing and Department of Chemical and Biochemical Engineering at the

Technical university of Denmark, the National Key R\&D Program of China (2017YFB0603401-03) as well as the National Natural Science Foundation of China (21425625) are greatly acknowledged for funding the project.

\section{References}

[1] N. Nishimura, H. Ohno, 15th anniversary of polymerised ionic liquids, Polymer. 55 (2014) 3289-3297.

[3] M. Armand, F. Endres, D.R. MacFarlane, H. Ohno, B. Scrosati, Ionic-liquid materials for the electrochemical challenges of the future, Nat. Mater. 8 (2009) 621-629. doi:10.1038/nmat2448. 
composites, J. Appl. Polym. Sci. 134 (2017). doi:10.1002/app.44767.

[5] W. Zhao, Y. Tang, J. Xi, J. Kong, Functionalized graphene sheets with poly(ionic liquid)s and high adsorption capacity of anionic dyes, Appl. Surf. Sci. 326 (2015) 276-284. doi:10.1016/j.apsusc.2014.11.069.

[6] T.P. Lodge, T. Ueki, Mechanically tunable, readily processable ion gels by self-assembly of block copolymers in ionic liquids, Acc. Chem. Res. 49 (2016) 2107-2114. doi:10.1021/acs.accounts.6b00308.

[7] A.M. Lopez, M.G. Cowan, D.L. Gin, R.D. Noble, Phosphonium-Based Poly(ionic liquid)/ionic liquid ion gel membranes: Influence of structure and ionic liquid loading on lon conductivity and light gas Separation Performance, J. Chem. Eng. Data. 63 (2018) 1154-1162. doi:10.1021/acs.jced.7b00541.

[8] D.B. Wijayasekara, M.G. Cowan, J.T. Lewis, D.L. Gin, R.D. Noble, T.S. Bailey, Elastic free-standing RTIL composite membranes for $\mathrm{CO}_{2} / \mathrm{N}_{2}$ separation based on sphere-forming triblock/diblock copolymer blends, J. Memb. Sci. 511 (2016) 170-179. doi:10.1016/j.memsci.2016.03.045.

[9] J. Ma, Y. Ying, X. Guo, H. Huang, D. Liu, C. Zhong, Fabrication of mixed-matrix membrane containing metal-organic framework composite with task-specific ionic liquid for efficient $\mathrm{CO}_{2}$ separation, J. Mater. Chem. A. 4 (2016) 7281-7288. doi:10.1039/c6ta02611g.

[10] J.L. Anthony, E.J. Maginn, J.F. Brennecke, Solubilities and thermodynamic properties of gases in the ionic liquid 1-n-butyl-3-methylimidazolium hexafluorophosphate, J. Phys. Chem. B. 106 (2002) 73157320. doi:10.1021/jp020631a.

[11] P. Scovazzo, J. Kieft, D.A. Finan, C. Koval, D. DuBois, R. Noble, Gas separations using nonhexafluorophosphate [PF6] ${ }^{-}$anion supported ionic liquid membranes, J. Memb. Sci. 238 (2004) 57-63. doi:10.1016/j.memsci.2004.02.033. 
[12] R.M. Teodoro, L.C. Tomé, D. Mantione, D. Mecerreyes, I.M. Marrucho, Mixing poly(ionic liquid)s and ionic liquids with different cyano anions: Membrane forming ability and $\mathrm{CO}_{2} / \mathrm{N}_{2}$ separation properties, J. Memb. Sci. 552 (2018) 341-348. doi:10.1016/j.memsci.2018.02.019.

[13] J.E. Bara, S. Lessmann, C.J. Gabriel, E.S. Hatakeyama, R.D. Noble, D.L. Gin, Synthesis and Performance of Polymerizable Room-Temperature Ionic Liquids as Gas Separation Membranes, Ind. Eng. Chem. Res. 46 (2007) 5397-5404. doi:10.1021/ie0704492.

[14] T.K. Carlisle, E.F. Wiesenauer, G.D. Nicodemus, D.L. Gin, R.D. Noble, Ideal $\mathrm{CO}_{2} /$ light gas separation performance of poly(vinylimidazolium) membranes and poly(vinylimidazolium)-ionic liquid composite films, Ind. Eng. Chem. Res. 52 (2013) 1023-1032. doi:10.1021/ie202305m.

[15] J.E. Bara, R.D. Noble, D.L. Gin, Effect of "free" cation substituent on gas separation performance of polymer-room-temperature ionic liquid composite membranes, Ind. Eng. Chem. Res. 48 (2009) 46074610. doi:10.1021/ie801897r.

[16] C. Vilela, N. Sousa, R.J.B. Pinto, A.J.D. Silvestre, F.M.L. Figueiredo, C.S.R. Freire, Exploiting poly(ionic liquids) and nanocellulose for the development of bio-based anion-exchange membranes, Biomass and Bioenergy. 100 (2017) 116-125. doi:10.1016/j.biombioe.2017.03.016.

[17] D. Gendron, A. Ansaldo, G. Bubak, L. Ceseracciu, G. Vamvounis, D. Ricci, Poly(ionic liquid)-carbon nanotubes self-supported, highly electroconductive composites and their application in electroactive devices, Compos. Sci. Technol. 117 (2015) 364-370. doi:10.1016/j.compscitech.2015.07.016.

[18] T. Fukushima, A. Kosaka, Y. Yamamoto, T. Aimiya, S. Notazawa, T. Takigawa, T. Inabe, T. Aida, Dramatic effect of dispersed carbon nanotubes on the mechanical and electroconductive properties of polymers derived from ionic liquids, Small. 2 (2006) 554-560. doi:10.1002/smll.200500404.

[19] A.S. Shaplov, S.M. Morozova, E.I. Lozinskaya, P.S. Vlasov, A.S.L. Gouveia, L.C. Tomé, I.M. Marrucho, 
Y.S. Vygodskii, Turning into poly(ionic liquid)s as a tool for polyimide modification: Synthesis, characterization and CO2separation properties, Polym. Chem. 7 (2016) 580-591. doi:10.1039/c5py01553g.

[20] P. Li, Q. Zhao, J.L. Anderson, S. Varanasi, M.R. Coleman, Synthesis of copolyimides based on room temperature ionic liquid diamines, J. Polym. Sci. Part A Polym. Chem. 48 (2010) 4036-4046. doi:10.1002/pola.24189.

[21] A.S. Rewar, S. V. Shaligram, U.K. Kharul, Polybenzimidazole based polymeric ionic liquids (PILs): Effects of controlled degree of $\mathrm{N}$-quaternization on physical and gas permeation properties, J. Memb. Sci. 497 (2016) 282-288. doi:10.1016/j.memsci.2015.09.019.

[22] R.S. Bhavsar, S.C. Kumbharkar, A.S. Rewar, U.K. Kharul, Polybenzimidazole based film forming polymeric ionic liquids: Synthesis and effects of cation-anion variation on their physical properties, Polym. Chem. 5 (2014) 4083-4096. doi:10.1039/c3py01709e.

[23] M. Lee, U.H. Choi, D. Salas-de la Cruz, A. Mittal, K.I. Winey, R.H. Colby, H.W. Gibson, Imidazolium Polyesters: Structure-Property Relationships in Thermal Behavior, Ionic Conductivity, and Morphology, Adv. Funct. Mater. 21 (2011) 708-717. doi:10.1002/adfm.201001878.

[24] B. Lin, L. Qiu, B. Qiu, Y. Peng, F. Yan, A soluble and conductive polyfluorene ionomer with pendant imidazolium groups for alkaline fuel cell applications, Macromolecules. 44 (2011) 9642-9649. doi:10.1021/ma202159d.

[25] A. Vollas, T. Chouliaras, V. Deimede, T. Ioannides, J. Kallitsis, A. Vollas, T. Chouliaras, V. Deimede, T. Ioannides, J. Kallitsis, New pyridinium type poly(Ionic Liquids) as membranes for $\mathrm{CO}_{2}$ separation, Polymers (Basel). 10 (2018) 912. doi:10.3390/polym10080912.

[26] R. Gao, M. Zhang, S.W. Wang, R.B. Moore, R.H. Colby, T.E. Long, Polyurethanes containing an 
imidazolium diol-based ionic-liquid chain extender for incorporation of ionic-liquid electrolytes, Macromol. Chem. Phys. 214 (2013) 1027-1036. doi:10.1002/macp.201200688.

[27] T.O. Magalhães, A.S. Aquino, F.D. Vecchia, F.L. Bernard, M. Seferin, S.C. Menezes, R. Ligabue, S. Einloft, Syntheses and characterization of new poly(ionic liquid)s designed for $\mathrm{CO}_{2}$ capture, RSC Adv. 4 (2014) 18164-18170. doi:10.1039/c4ra00071d.

[28] C. Hirschl, L. Neumaier, S. Puchberger, W. Mühleisen, G. Oreski, G.C. Eder, R. Frank, M. Tranitz, M. Schoppa, M. Wendt, N. Bogdanski, A. Plösch, M. Kraft, Determination of the degree of ethylene vinyl acetate crosslinking via Soxhlet extraction: Gold standard or pitfall?, Sol. Energy Mater. Sol. Cells. 143 (2015) 494-502. doi:10.1016/j.solmat.2015.07.043.

[29] Z. Dai, L. Ansaloni, D.L. Gin, R.D. Noble, L. Deng, Facile fabrication of $\mathrm{CO}_{2}$ separation membranes by cross-linking of poly(ethylene glycol) diglycidyl ether with a diamine and a polyamine-based ionic liquid, J. Memb. Sci. 523 (2017) 551-560. doi:10.1016/j.memsci.2016.10.026.

[30] E. Karjalainen, D.J. Wales, D.H.A.. Gunasekera, J. Dupont, P. Licence, R.D. Wildman, V. Sans, Tunable ionic control of polymeric films for inkjet based 3D printing, ACS Sustain. Chem. Eng. 6 (2018) 39843991. doi:10.1021/acssuschemeng.7b04279.

[31] H.M.L. Thijs, C.R. Becer, C. Guerrero-Sanchez, D. Fournier, R. Hoogenboom, U.S. Schubert, Water uptake of hydrophilic polymers determined by a thermal gravimetric analyzer with a controlled humidity chamber, J. Mater. Chem. 17 (2007) 4864-4871. doi:10.1039/b711990a.

[32] T. Kelen, F. Tüdös, Analysis of the Linear Methods for Determining Copolymerization Reactivity Ratios. I. A new improved linear graphic method, J. Macromol. Sci. Part A - Chem. 9 (1975) 1-27. doi:10.1080/00222337508068644.

[33] J.P. Kennedy, T. Kelen, F. Tüdös, Analysis of the linear methods for determining copolymerization 
reactivity ratios. II. A critical reexamination of cationic monomer reactivity ratios, J. Polym. Sci. Polym. Chem. Ed. 13 (1975) 2277-2289. doi:10.1002/pol.1975.170131010.

[34] J.E. Bara, C.J. Gabriel, S. Lessmann, T.K. Carlisle, A. Finotello, D.L. Gin, R.D. Noble, Enhanced $\mathrm{CO}_{2}$ separation selectivity in oligo(ethylene glycol) functionalized room-temperature ionic liquids, Ind. Eng. Chem. Res. 46 (2007) 5380-5386. doi:10.1021/ie070437g.

[35] J.E. Bara, D.L. Gin, R.D. Noble, Effect of anion on gas separation performance of polymer-roomtemperature ionic liquid composite membranes, Ind. Eng. Chem. Res. 47 (2008) 9919-9924. doi:10.1021/ie801019x.

[36] T. Feng, B. Lin, S. Zhang, N. Yuan, F. Chu, M.A. Hickner, C. Wang, L. Zhu, J. Ding, Imidazolium-based organic-inorganic hybrid anion exchange membranes for fuel cell applications, J. Memb. Sci. 508 (2016) 7-14. doi:10.1016/j.memsci.2016.02.019.

[37] A. Sayari, Y. Belmabkhout, R. Serna-Guerrero, Flue gas treatment via $\mathrm{CO}_{2}$ adsorption, Chem. Eng. J. 171 (2011) 760-774. doi:10.1016/j.cej.2011.02.007.

[38] H.D. Nguyen, D. Löf, S. Hvilsted, A.E. Daugaard, Highly branched bio-based unsaturated polyesters by enzymatic polymerization, Polymers. 8 (2016) 363. doi:10.3390/polym8100363.

[39] G. Zarca, W.J. Horne, I. Ortiz, A. Urtiaga, J.E. Bara, Synthesis and gas separation properties of poly(ionic liquid)-ionic liquid composite membranes containing a copper salt, J. Memb. Sci. 515 (2016) 109-114. doi:10.1016/j.memsci.2016.05.045.

[40] D.J.C. H. B. Park, C. H. Jung, Y.M. Lee, A. J. Hill, S. J. Pas, S. T. Mudie, E. V. Wagner, B. D. Freeman, Polymers with cavities tuned for fast selective transport of small molecules and ions, Science. 318 (2007) 254-258. doi:DOI: 10.1126/science.1146744. 
449 [41] H. Lin, E. Van Wagner, R. Raharjo, B.D. Freeman, I. Roman, High-performance polymer membranes for natural-gas sweetening, Adv. Mater. 18 (2006) 39-44. doi:10.1002/adma.200501409.

451 [42] Z. Ma, Z. Qiao, Z. Wang, X. Cao, Y. He, J. Wang, S. Wang, $\mathrm{CO}_{2}$ separation enhancement of the membrane by modifying the polymer with a small molecule containing amine and ester groups, RSC Adv.

\section{4} 455 456 457 458 4 (2014) 21313. doi:10.1039/c4ra01107d.

[43] X. Zhou, M.M. Obadia, S.R. Venna, E.A. Roth, A. Serghei, D.R. Luebke, C. Myers, Z. Chang, R. Enick, E. Drockenmuller, H.B. Nulwala, Highly cross-linked polyether-based 1,2,3-triazolium ion conducting membranes with enhanced gas separation properties, Eur. Polym. J. 84 (2016) 65-76. doi:10.1016/j.eurpolymj.2016.09.001. 
1. A range of poly(VIm-co-BuA) were prepared from 1-vinylimidazole and butyl acrylate

2. Reactivity ratios of VIm and BuA were determined through NLLSQ and Kelen and Tüdos

3. Poly(RT-IL) membranes were prepared by one-pot quarternization and cross linking

4. Poly(RT-IL) membranes were tested for permeability, $\mathrm{CO}_{2} / \mathrm{N}_{2}$ and $\mathrm{CO}_{2} / \mathrm{CH}_{4}$ selectivity 